\title{
Efeitos da seleção para peso pós-desmame sobre características de carcaça e rendimento de cortes cárneos comerciais de bovinos ${ }^{1}$
}

\section{Sarah Figueiredo Martins Bonilha², Irineu Umberto Packer ${ }^{3}$, Leopoldo Andrade de Figueiredo², Guilherme Fernando Alleoni ${ }^{4}$, Flávio Dutra de Resende ${ }^{5}$, Alexander George Razook ${ }^{6}$}

\footnotetext{
1 Parte da dissertação de mestrado apresentada à ESALQ/USP pela primeira autora.

2 Instituto de Zootecnia, Centro APTA Bovinos de Corte.

${ }^{3}$ Departamento de Zootecnia da ESALQ/USP. Bolsista do CNPq.

4 Instituto de Zootecnia, Sede-Nova Odessa.

${ }^{5}$ APTA, PRDTA Alta Mogiana.

${ }^{6}$ Instituto de Zootecnia, Centro APTA Bovinos de Corte. Bolsista do CNPq.
}

RESUMO - Foram avaliados os efeitos da seleção para peso pós-desmame sobre características de carcaça e rendimento de cortes cárneos comerciais de 44 bovinos machos não-castrados selecionados ou não para peso aos 378 dias, nascidos em 1999 , Foram utilizados animais dos grupos genéticos Nelore Seleção (NeS), Nelore Controle (NeC) e Caracu Seleção (Ca). Os animais foram distribuídos aleatoriamente em duas categorias experimentais: grupo de alimentação restrita (AR) e grupo de alimentação ad libitum (AL). Em ambas as categorias, foram alocados oito animais dos grupos genéticos NeS e Ca e seis animais do grupo NeC. O período experimental foi determinado pelo tempo de acabamento dos animais, ou seja, quando atingiram, no mínimo, $4 \mathrm{~mm}$ de espessura de gordura subcutânea, avaliada por ultra-som, sobre o músculo Longissimus dorsi, na posição entre a 12 a e $13^{\text {a }}$ costelas. Em cada grupo genético, à medida que o acabamento preconizado para cada animal da categoria AL foi atingido, o animal da categoria AR mais semelhante quanto ao peso e à condição corporal no início do experimento foi também abatido. O efeito do grupo genético foi significativo para a maioria das características estudadas, porém, não houve interação significativa entre grupos genéticos e regimes alimentares. Os animais Ca e NeS tiveram maiores pesos de abate, sendo que animais Ca necessitaram de mais tempo de confinamento para atingirem o ponto de acabamento preconizado. O maior peso de abate desses animais também influenciou outras características correlacionadas, como pesos de carcaça, traseiro, dianteiro e ponta-de-agulha. A seleção para peso aumentou os pesos de abate, de carcaça e dos cortes primários. Os animais NeS apresentaram carne menos macia, mas ainda dentro dos padrões de maciez considerados satisfatórios (força de cisalhamento abaixo de 5 kgf).

Palavras-chave: Caracu, carcaça, maciez da carne, Nelore, seleção

\section{Effects of selection for post weaning weight on carcass traits and meat cut yields of beef cattle}

\begin{abstract}
Data from 44 bulls of the genetic groups Selection Nellore (NeS), Control Nellore (NeC) and Caracu (Ca) herds born in 1999 were used to evaluate the effects of selection for post weaning weight on carcass traits and meat cuts yields at 378 days of age (P 378). The animals were randomly distributed into two experimental classes: restricted feeding (AR) and ad libitum feeding (AL) including 8 animals from the NeS and Ca groups and 6 animals from the NeC group. Animals of each class were slaughtered in pairs when the animals AL group reached $4 \mathrm{~mm}$ of ultrasonic fat thickness on Longissimus dorsi muscle, between the $12^{\text {th }}$ and $13^{\text {th }}$ ribs. The interaction between genetic group and feeding class was not significant for most of the traits evaluated. The genetic group effect was significant. Animals of the Ca and NeS groups were heavier at slaughter and Ca animals required longer feedlot period to reach the desired fat thickness. Higher slaughter weights of these animals changed their carcass, hindquarter, forequarter and spare ribs weights. The selection for P 378 in the Nellore group resulted in heavier weights at slaughter, heavier carcasses and primary cuts, but lower meat tenderness, although within reasonable values of shear force (below $5.0 \mathrm{kgf}$ ).
\end{abstract}

Key Words: Caracu, carcass, meat tenderness, Nellore, selection

\section{Introdução}

O sistema produtivo de carne bovina exige cada vez mais produção eficiente em curto espaço de tempo, com produto de melhor qualidade, obtido pelo uso de animais geneticamente superiores, em condições ambientais adequadas.

As raças exploradas ou o manejo adotado influenciam o peso final de abate, a precocidade e o acabamento do animal. Algumas características importantes da carcaça, 
como a carne aproveitável, a cobertura de gordura, os subprodutos da desossa, a maciez, entre outras, estão intimamente relacionadas à idade de abate do animal, ao seu grau de acabamento e ao seu peso de carcaça (Morris et al., 1993).

Segundo Marshal (1994), características de carcaça, como peso, carne aproveitável, gordura aparada e ossos, apresentam estimativas de herdabilidade que variam de média a alta. Assim, a análise das características de carcaça de diferentes grupos genéticos torna-se interessante, pois são transmissíveis através das gerações.

Os cortes básicos da carcaça de bovinos no mercado brasileiro são o dianteiro com cinco costelas, que compreende o acém e a paleta, o costilhar ou ponta-de-agulha e o traseiro especial ou serrote, que inclui o coxão e a alcatra completa (Peron et al., 1993). Economicamente, é desejável maior rendimento do traseiro especial em relação a outros cortes, em virtude de seu maior valor comercial.

Com o projeto de melhoramento genético da Estação Experimental de Zootecnia de Sertãozinho-SP (EEZS-SP, atual Centro APTA - Bovinos de Corte), tem-se como objetivo principal o aumento da taxa de crescimento dos animais, por meio de seleção para peso pós-desmame. Além das mudanças nas características de crescimento, analisadas desde o início do programa de seleção, tornou-se fundamental também o acompanhamento das mudanças nas características de qualidade da carne. Alguns estudos publicados apresentam análises de características de carcaça envolvendo indivíduos dos rebanhos selecionados (Nardon et al., 2001a,b; Resende et al., 2000; Razook et al., 2001; Vittori et al., 2006).

Realizou-se este estudo com o objetivo de dar continuidade às avaliações da carcaça e da qualidade da carne de grupos contemporâneos dos rebanhos Nelore e Caracu da EEZS-SP (atual Centro APTA - Bovinos de Corte) selecionados para peso e pertencentes à 19a progênie destas linhas de seleção.

\section{Material e Métodos}

Como animais experimentais foram utilizados 44 machos não-castrados provenientes dos rebanhos Nelore Seleção (NeS) e Caracu (Ca), selecionados para peso aos 378 dias de idade(P378), e Nelore Controle(NeC), animais não-selecionados que apresentaram diferencial de seleção nulo no caráter, da EEZS-SP (atual Centro APTA - Bovinos de Corte). Esses animais, nascidos em 1999, participaram das Provas de Ganho de Peso (PGP) de 2000, segundo regras descritas por Razook et al. (1997). Ao final da PGP, foram escolhidos 12 animais do grupo $\mathrm{NeC}$ e 16 dos $\mathrm{NeS}$ e Ca, de modo a representar a média do peso padronizado aos 378 dias de cada rebanho.

A fase de confinamento foi realizada na Estação Experimental de Zootecnia de Colina (atual Polo APTA Alta Mogiana), quando os animais apresentavam, em média, 18 meses de idade e pesos médios de 434, 404 e 345 $\mathrm{kg}$, respectivamente, para os grupos genéticos $\mathrm{Ca}$, NeS e $\mathrm{NeC}$. Os animais foram divididos em pares, de acordo com a semelhança na condição corporal, obedecendo ao peso médio da Prova de Ganho de Peso em cada grupo genético. Dentro de cada par, foram sorteados dois regimes alimentares: ad libitum - alimentação à vontade; e restrito fornecimento de $65 \mathrm{~g} \mathrm{MS} / \mathrm{kg}$ de peso metabólico, procurando suprir as exigências de mantença. Balancearam-se as dietas com silagem de milho, milho moído, farelo de algodão, uréia, rumensin e mistura mineral. As dietas foram reajustadas semanalmente, com base no consumo e na porcentagem de MS do volumoso e do concentrado.

O período de adaptação teve duração de 28 dias, quando todos os animais receberam a dieta utilizada no regime ad libitum. Na entrada do período de adaptação do experimento, os animais foram pesados e tiveram suas condições corporais avaliadas via ultra-som e escore corporal. A pesagem e as medidas de ultra-som e escore corporal foram repetidas a cada 28 dias.

Em cada grupo genético, à medida que um animal do grupo ad libitum atingia o acabamento preconizado (mínimo de $4 \mathrm{~mm}$ de espessura de gordura, medida pelo ultra-som sobre o músculo Longissimus dorsi na posição entre a 12a e a $13^{\underline{a}}$ costelas), este era abatido juntamente com seu par do grupo restrito.

Os animais foram abatidos aproximadamente aos 22 meses de idade e os pesos vivos médios de abate observados foram: $\mathrm{NeS}$ ad libitum $=526,8 \mathrm{~kg} ; \mathrm{NeS}$ restrito = $456,8 \mathrm{~kg} ; \mathrm{NeC}$ ad libitum $=445,0 \mathrm{~kg} ; \mathrm{NeC}$ restrito $=406,0 \mathrm{~kg}$; Ca ad libitum $-562,5 \mathrm{~kg}$; e Ca restrito $=486,5 \mathrm{~kg}$. O abate foi feito no Frigorífico Minerva, localizado na cidade de Barretos-SP, e obedeceu ao procedimento normal de um frigorífico sob inspeção federal.

As carcaças foram mantidas em câmara de resfriamento a aproximadamente $2^{\circ} \mathrm{C}$ por 24 horas. As meias-carcaças direitas resfriadas foram divididas em dianteiro (cinco costelas), ponta-de-agulha e traseiro especial. Posteriormente, foram separadas nos seguintes cortes comerciais: contrafilé, filé-mignon, alcatra, patinho, coxão-mole, coxão-duro, lagarto, capa e aba, paleta, pescoço, acém, peito, cupim, músculos e ponta-de-agulha desossada e aparada.

Após a separação, cada corte foi pesado individualmente. As aparas e os ossos também foram pesados e 
registrados quanto aos seus respectivos cortes primários: dianteiro, ponta-de-agulha e traseiro especial.

Para análise qualitativa da carne, retiraram-se amostras (bifes de 2,5 cm de espessura) do músculo Longissimus dorsi, na altura da $12^{-}$costela. As amostras foram embaladas a vácuo e congeladas. Posteriormente, foram transferidas para uma câmara de resfriamento (a $2^{\circ} \mathrm{C}$, por 12 horas) até o momento das análises de maciez e perdas por cozimento. Os bifes foram assados em forno (em torno de $170^{\circ} \mathrm{C}$ ) e o controle da temperatura das amostras foi feito por termômetros individuais, colocados no seu centro geométrico. Quando a temperatura interna atingiu aproximadamente $70^{\circ} \mathrm{C}$, as amostras foram retiradas do forno e mantidas em temperatura ambiente. Determinaram-se as perdas por evaporação e drenagem durante o cozimento. Foram retiradas seis amostras cilíndricas (aproximadamente 13 mm de diâmetro) de cada bife, no sentido das fibras musculares, com o auxílio de um vazador manual. Determinou-se a força de cisalhamento com o aparelho Warner-Bratzler Shear Force, fabricado pela GR Eletrical Manufacturing Company, com capacidade para $25 \mathrm{~kg}$.

Odelineamento experimental foi inteiramente casualizado, com arranjo fatorial $3 \times 2$, composto de três grupos genéti$\cos (\mathrm{Ca}, \mathrm{NeS}$ e $\mathrm{NeC}$ ) e dois regimes alimentares (ad libitum e restrito). Utilizou-se a análise de variância para testar os efeitos dos grupos genéticos, dos regimes alimentares e da interação e aplicou-se o teste Tukey a 5\% de probabilidade para comparação das médias dos grupos genéticos. Todas as análises estatísticas foram realizadas pelo PROC GLM do SAS (1999).

\section{Resultados e Discussão}

Não houve interação significativa regime alimentar $\times$ grupo genético para as características estudadas. Entretanto, os efeitos principais de regime alimentar e grupo genético foram significativos para todas características analisadas.

Algumas características analisadas, como tempo de confinamento, rendimentos de aparas, pesos de alguns cortes de traseiro e dianteiro, força de cisalhamento e espessura de gordura, apresentaram altos coeficientes de variação, indicando grandes variações nos dados utilizados para os cálculos das médias.

Os animais foram avaliados quanto às características de produção e qualidade de carne, porém, apenas as diferenças entre $\mathrm{NeS}$ e $\mathrm{NeC}$ podem ser consideradas conseqüência de seleção, uma vez que ambos os rebanhos foram originados da mesma população-base. No rebanho Ca, embora a seleção tenha iniciado simultaneamente, há diferenças raciais, as mais evidentes relacionadas ao tamanho. Os animais pertencentes ao grupo ad libitum, quando comparados aos do grupo restrito, apresentaram sempre maiores médias, pois não sofreram restrição alimentar.

Comparando-se os rebanhos Ca e NeS (Tabela 1), os animais Ca apresentaram dianteiro (embora a diferença não tenha sido significativa) e ponta-de-agulha mais pesados. Para o frigorífico interessa, entre outros fatores, carcaças mais pesadas, com maior rendimento de traseiro e de seus cortes básicos aparados, embora esse interesse não signifique vantagens econômicas adicionais ao produtor, que recebe basicamente pelo peso da carcaça.

Animais $\mathrm{NeS}$ e Ca foram similares quanto ao pesos de abate e da meia-carcaça direita, no entanto, foram superiores em relação aos NeC. Os animais Ca diferiram significativamente dos $\mathrm{NeC}$ quanto ao tempo de confinamento, pois necessitaram de um período maior para atingirem $4 \mathrm{~mm}$ de espessura de gordura. Essas diferenças no peso de carcaça

Tabela 1 - Médias de tempo de confinamento (dias), peso vivo ao abate $(\mathrm{kg})$, peso da meia-carcaça direita resfriada $(\mathrm{kg})$ e peso $(\mathrm{kg})$ e rendimento (\%) dos cortes primários de bovinos Nelore e Caracu selecionados (NeS e Ca) e Nelore Controle ( $\mathrm{NeC}$ )

Table 1 - $\quad$ Means for feedlot period (days), live weight at slaughter $(\mathrm{kg})$, cold right carcass weight $(\mathrm{kg})$, prime cuts weight $(\mathrm{kg})$ and prime cut percentages (\%) of selected Nellore and Caracu (NeS and $\mathrm{Ca})$ and control Nellore ( $\mathrm{NeC}$ ) groups

\begin{tabular}{|c|c|c|c|c|}
\hline & \multicolumn{3}{|c|}{$\begin{array}{l}\text { Grupo } \\
\text { Group }\end{array}$} & \multirow[t]{2}{*}{ CV (\%) } \\
\hline & $\mathrm{Ca}$ & $\mathrm{NeS}$ & $\mathrm{NeC}$ & \\
\hline $\begin{array}{l}\text { Tempo de confinamento } \\
\text { Feedlot period }\end{array}$ & $130 \mathrm{a}$ & $115 a b$ & $104 b$ & 21,28 \\
\hline $\begin{array}{l}\text { Peso vivo } \\
\text { Live weight }\end{array}$ & $525,6 a$ & $493,1 \mathrm{a}$ & $424,3 b$ & 7,80 \\
\hline $\begin{array}{l}\text { Peso carcaça direita } \\
\text { Right carcass weight }\end{array}$ & $149,5 a$ & $143,7 a$ & $124,6 b$ & 9,79 \\
\hline \multicolumn{5}{|l|}{$\begin{array}{l}\text { Quartos (kg) } \\
\text { Quarters }\end{array}$} \\
\hline $\begin{array}{l}\text { Traseiro especial } \\
\text { Hindquarter }\end{array}$ & $66,11 \mathrm{a}$ & $66,06 a$ & $58,10 b$ & 9,30 \\
\hline $\begin{array}{l}\text { Dianteiro } \\
\text { Forequarter }\end{array}$ & $63,65 a$ & $60,46 a$ & $52,15 b$ & 11,34 \\
\hline $\begin{array}{l}\text { Ponta-de-agulha } \\
\text { Spare ribs }\end{array}$ & $19,37 a$ & $17,08 \mathrm{~b}$ & $14,73 c$ & 12,14 \\
\hline
\end{tabular}

Rendimento dos quartos (\%)

Carcass quarters

$\begin{array}{lcccc}\begin{array}{l}\text { Traseiro especial } \\ \text { Hindquarter }\end{array} & 44,3 \mathrm{~b} & 46,1 \mathrm{a} & 46,7 \mathrm{a} & 3,09 \\ \begin{array}{l}\text { Dianteiro } \\ \text { Forequarter }\end{array} & 42,6 \mathrm{a} & 42,0 \mathrm{a} & 41,4 \mathrm{a} & 3,91 \\ \begin{array}{l}\text { Ponta-de-agulha } \\ \text { Spare ribs }\end{array} & 12,9 \mathrm{a} & 11,8 \mathrm{~b} & 11,8 \mathrm{~b} & 5,90 \\ \end{array}$

Médias com mesma letra nas linhas não diferem significativamente pelo teste Tukey a $5 \%$ de probabilidade.

Means followed by the same letter within a row do not differ $(P<0.05)$ by Tukey test. 
refletiram também nos pesos dos quartos traseiro, dianteiro e ponta-de-agulha, denotando que animais Nelore são superiores aos Caracu quanto ao rendimento de traseiro especial e inferiores quanto ao rendimento de ponta-de-agulha. Os rendimentos de dianteiro não diferiram entre os três grupos genéticos.

Não houve diferença significativa entre os três grupos genéticos estudados (Tabela 2) quanto às características de porção comestível. A porcentagem de ossos não diferiu entre os grupos $\mathrm{NeS}$ e $\mathrm{NeC}$, tanto para o total da carcaça como para os quartos. Os animais Ca possuem porcentagens de ossos semelhantes a de animais NeS, porém em maior proporção para traseiro e dianteiro. A porcentagem de aparas não diferiu entre os três grupos genéticos.

Comparando os grupos $\mathrm{NeS}$ e $\mathrm{NeC}$, observou-se que os valores de cortes aparados importantes do traseiro

Tabela 2 - Rendimentos (\%) da porção comestível, de ossos e de aparas obtidos na meia-carcaça direita e em seus respectivos quartos de bovinos Nelore e Caracu selecionados (NeS e Ca) e Nelore Controle ( $\mathrm{NeC})$

Table 2 - Means for edible parts, bones and shavings (\%) from right halfcarcass and their respective quarters of selected Nellore and Caracu (NeS and $\mathrm{Ca}$ ) and control Nellore ( $\mathrm{NeC}$ ) groups

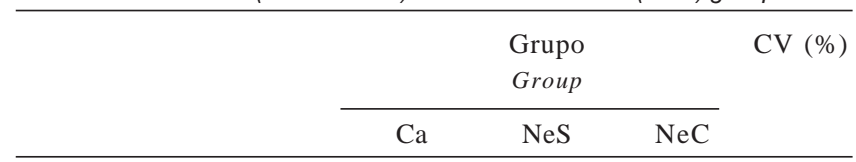

Porção comestível (\%)

Edible parts (\%)

\begin{tabular}{|c|c|c|c|c|}
\hline $\begin{array}{l}\text { Traseiro } \\
\text { Hindquarter }\end{array}$ & $65,6 a$ & $67,3 a$ & $67,1 \mathrm{a}$ & 3,98 \\
\hline Dianteiro & $66,7 a$ & $67,6 a$ & $67,1 \mathrm{a}$ & 5,75 \\
\hline Forequarter & & & & \\
\hline $\begin{array}{l}\text { Ponta-de-agulha } \\
\text { Spare ribs }\end{array}$ & $71,8 \mathrm{a}$ & $69,4 a$ & $71,4 a$ & 5,83 \\
\hline Total & $66,8 a$ & $67,6 a$ & $67,6 a$ & 3,43 \\
\hline \multicolumn{5}{|l|}{ Ossos (\%) } \\
\hline $\begin{array}{l}\text { Traseiro } \\
\text { Hindquarter }\end{array}$ & $20,6 a$ & $19,7 \mathrm{ab}$ & $19,1 b$ & 6,60 \\
\hline $\begin{array}{l}\text { Dianteiro } \\
\text { Forequarter }\end{array}$ & $19,8 a$ & $19,5 a b$ & $18,5 b$ & 6,64 \\
\hline $\begin{array}{l}\text { Ponta-de-agulha } \\
\text { Spare ribs }\end{array}$ & $15,9 a$ & $16,6 \mathrm{a}$ & $16,7 \mathrm{a}$ & 14,87 \\
\hline Total & $19,6 a$ & $19,2 \mathrm{a}$ & $18,6 a$ & 6,07 \\
\hline \multicolumn{5}{|l|}{ Aparas (\%) } \\
\hline $\begin{array}{l}\text { Traseiro } \\
\text { Hindquarter }\end{array}$ & $9,7 a$ & $9,3 a$ & $8,7 a$ & 35,75 \\
\hline $\begin{array}{l}\text { Dianteiro } \\
\text { Forequarter }\end{array}$ & $12,2 \mathrm{a}$ & $12,6 a$ & $15,0 \mathrm{a}$ & 27,84 \\
\hline $\begin{array}{l}\text { Ponta-de-agulha } \\
\text { Spare ribs }\end{array}$ & $11,4 \mathrm{a}$ & $13,5 \mathrm{a}$ & $13,1 \mathrm{a}$ & 32,63 \\
\hline Total & $11,0 \mathrm{a}$ & $11,1 \mathrm{a}$ & $11,9 a$ & 19,10 \\
\hline
\end{tabular}

Médias com mesma letra nas linhas não diferem $(P<0,05)$ pelo teste Tukey a $5 \%$ de probabilidade.

Means followed by the same letter within a row do not differ $(P<0.05)$ by Tukey test.
(Tabela 3), como filé-mignon, alcatra, patinho, coxão mole e lagarto, foram maiores nos animais NeS. Os maiores valores no peso dos cortes aparados dos animais selecionados foram influenciados pelo maior peso de carcaça desses animais. Esperava-se menor valor de cupim para os animais $\mathrm{NeC}$, em comparação aos $\mathrm{NeS}$, o que de fato ocorreu, porém não significativamente. Uma vez que os animais Ca

Tabela 3 - Peso médio dos cortes aparados, em kg, retirados da meia-carcaça direita dos bovinos Nelore e Caracu selecionados ( $\mathrm{NeS}$ e $\mathrm{Ca}$ ) e Nelore Controle ( $\mathrm{NeC}$ )

Table 3 - Means for trimmed cuts $(\mathrm{kg})$ from right half-carcass of selected Nellore and Caracu ( $\mathrm{NeS}$ and $\mathrm{Ca}$ ) and control Nellore ( $\mathrm{NeC}$ ) groups

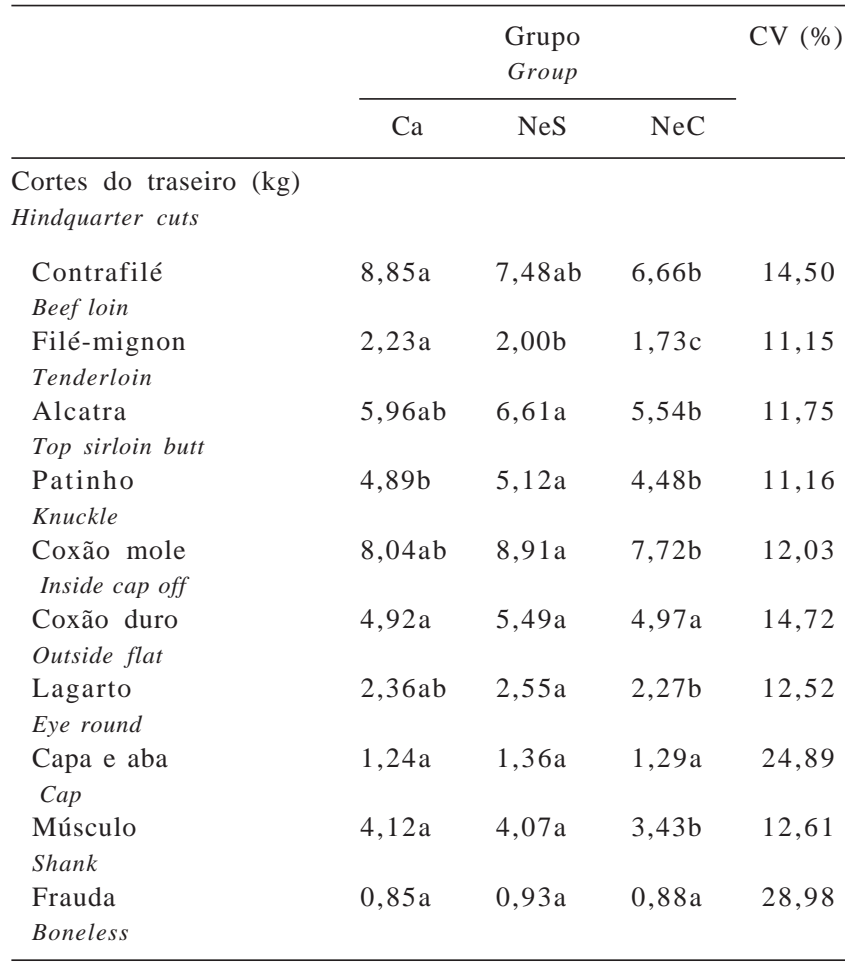

Cortes do dianteiro $(\mathrm{kg})$

Forequarter cuts

\begin{tabular}{|c|c|c|c|c|}
\hline \multicolumn{5}{|l|}{$\begin{array}{l}\text { Paleta } \\
\text { Shoulder clod }\end{array}$} \\
\hline Pescoço & $5,61 \mathrm{a}$ & $5,01 \mathrm{a}$ & $4,45 a$ & 27,39 \\
\hline Neck & & & & \\
\hline $\begin{array}{l}\text { Acém } \\
\text { Beef chuck }\end{array}$ & $13,22 \mathrm{a}$ & $9,97 b$ & $7,97 \mathrm{c}$ & 18,18 \\
\hline $\begin{array}{l}\text { Peito } \\
\text { Beef brisket }\end{array}$ & $8,12 \mathrm{a}$ & $7,08 \mathrm{ab}$ & $6,26 b$ & 18,01 \\
\hline $\begin{array}{l}\text { Cupim } \\
\text { Hump }\end{array}$ & $0,73 b$ & $4,31 \mathrm{a}$ & $4,08 \mathrm{a}$ & 52,49 \\
\hline $\begin{array}{l}\text { Músculos } \\
\text { Beef foreshank }\end{array}$ & $3,94 a$ & $4,03 a$ & $3,00 \mathrm{~b}$ & 19,84 \\
\hline $\begin{array}{l}\text { onta-de-agulha } \\
\text { pare ribs }\end{array}$ & & & & \\
\hline $\begin{array}{l}\text { Ponta-de-agulha } \\
\text { Beef plate }\end{array}$ & $13,95 a$ & $11,83 b$ & $10,48 b$ & 12,49 \\
\hline
\end{tabular}

Médias com mesma letra nas linhas não diferem significativamente pelo teste Tukey a $5 \%$ de probabilidade.

Means followed by the same letter within a row do not differ $(P<0.05)$ by Tukey test. 
apresentaram valor bem inferior para o peso desse corte, a variação na característica foi muito grande, o que provavelmente contribuiu para que a diferença entre $\mathrm{NeS}$ e $\mathrm{NeC}$ não tivesse sido significativa. Nardon (2001b), comparando animais $\mathrm{NeC}$ e $\mathrm{NeS}$ pertencentes aos rebanhos de Sertãozinho, também não encontrou diferenças significativas para o corte cupim entre animais $\mathrm{NeS}$ e $\mathrm{NeC}$ de progênies nascidas de 1992 a 1994.

As diferenças significativas observadas entre $\mathrm{NeS}$ e $\mathrm{NeC}$ (Tabela 4) refletem mudanças correlacionadas nas características da carcaça como conseqüência da seleção para peso pós-desmame. O processo de seleção aplicado aos animais proporcionou mudança genética média estimada de 46,4 kg no peso aos 378 dias de idade (P378) para os Nelore selecionados em 15 anos de progênies em comparação aos Nelore não-selecionados (Razook et al., 1998). Conseqüentemente, os pesos de abate e de carcaça também refletiram estes efeitos, bem como as diferentes taxas de crescimento apresentadas pelos grupos genéticos durante o período de terminação.

O peso dos quartos nos animais NeS foi significativamente maior que nos animais $\mathrm{NeC}$. Essa superioridade foi relativamente proporcional ao progresso genético de 1,1\% ao ano mencionado por Razook et al. (1998) para mudança em P378.

Os valores semelhantes para rendimentos de aparas e de porção comestível quando o grupo NeS foi comparado

Tabela 4 - Força de cisalhamento $(\mathrm{kg})$, perdas no cozimento (\%), área de olho-de-lombo $1\left(\mathrm{~cm}^{2}\right)$, área de olho-delombo $2\left(\mathrm{~cm}^{2} / 100 \mathrm{~kg}\right.$ de carcaça) e espessura de gordura $(\mathrm{mm})$, medidas no contrafilé dos bovinos Nelore e Caracu selecionados (NeS e $\mathrm{Ca}$ ) e Nelore Controle $(\mathrm{NeC})$

Table 4 - $\quad$ Means for shear force $(\mathrm{kg})$, cooking losses (\%), rib eye area $1\left(\mathrm{~cm}^{2}\right)$, rib eye area $2\left(\mathrm{~cm}^{2} / 100 \mathrm{~kg}\right.$ carcass) and fat thickness in loin of selected Nellore and Caracu (NeS and Ca) and control Nellore ( $\mathrm{NeC}$ ) groups

\begin{tabular}{|c|c|c|c|c|}
\hline & \multicolumn{3}{|c|}{$\begin{array}{l}\text { Grupo } \\
\text { Group }\end{array}$} & \multirow[t]{2}{*}{ CV (\%) } \\
\hline & $\mathrm{Ca}$ & $\mathrm{NeS}$ & $\mathrm{NeC}$ & \\
\hline $\begin{array}{l}\text { Força de cisalhamento } \\
\text { Shear force }\end{array}$ & $3,06 a$ & $4,25 b$ & $3,17 a$ & 29,58 \\
\hline $\begin{array}{l}\text { Perdas no cozimento } \\
\text { Cooking losses }\end{array}$ & $22,1 \mathrm{a}$ & $23,7 a$ & $22,9 a$ & 15,58 \\
\hline $\begin{array}{l}\text { Área de olho-de-lombo } 1 \\
\text { Rib eye area } 1\end{array}$ & $76,94 a$ & $65,94 b$ & $64,75 b$ & 11,42 \\
\hline $\begin{array}{l}\text { Área de olho-de-lombo } 2 \\
\text { Rib eye area } 2\end{array}$ & $25,84 a$ & $23,17 b$ & $26,11 \mathrm{a}$ & 12,34 \\
\hline $\begin{array}{l}\text { Espessura de gordura } \\
\text { Fat thickness }\end{array}$ & $4,5 b$ & $5,8 a$ & $6,6 a$ & 35,21 \\
\hline
\end{tabular}

Médias com mesma letra nas linhas não diferem $(P<0,05)$ pelo teste Tukey a $5 \%$ de probabilidade.

Means followed by the same letter within a row do not differ $(P<0.05)$ by Tukey test. ao $\mathrm{NeC}$ foram coerentes com as observações de Nour \& Thonney (1987) e de Owens et al. (1993). Morris et al. (1993) observaram diferenças significativas entre animais selecionados e controle quanto às características peso da porção comestível da carcaça, traseiro, dianteiro e peso dos ossos, porém, não observaram diferenças para o peso de aparas.

Norman \& Felício (1981), em experimento com as raças Charolesa, Canchim, Nelore e Guzerá, observaram que, entre as características estudadas, os animais das duas primeiras raças apresentaram menos aparas de gordura que os das raças Nelore e Guzerá. Além disso, foram iguais ou melhores que os das raças zebuínas quanto à quantidade de porção comestível e à produção de carne de primeira qualidade.

Neste trabalho, os animais Ca foram bem semelhantes aos NeS quanto ao peso dos cortes. Diferenças significativas foram detectadas apenas para os cortes filé-mignon, patinho, acém e ponta-de-agulha, no entanto, esta superioridade dos animais Ca pode ser explicada pelo seu maior comprimento, o que também se reflete no contrafilé, embora a diferença de $+1,37 \mathrm{~kg}$ não tenha sido significativa. Para o corte patinho, o maior valor encontrado para os animais NeS pode ser explicado pela melhor conformação de pernil desse grupo, sendo comumente esperado que animais da raça Caracu apresentem, em geral, traseiro mais descarnado. Esses resultados são coerentes com os encontrados por Nardon (2001b).

Neste estudo, verificou-se influência dos grupos genéticos sobre a força de cisalhamento. O grupo $\mathrm{NeS}$ apresentou maior média para força de cisalhamento, o que pode indicar carne menos macia, apesar de o valor encontrado $(4,25 \mathrm{~kg})$ ainda ser indicativo de carne macia. Alleoni et al. (1997) não encontraram diferenças significativas para força de cisalhamento entre animais das raças Nelore e Caracu. Nardon et al. (2001b) encontraram valores menores de força de cisalhamento apenas para animais Caracu. Segundo Leme et al. (2002), valores de força de cisalhamento inferiores a $4,5 \mathrm{~kg}$ são bem aceitos como padrão de maciez. O valor encontrado para $\mathrm{NeC}$ diferiu daqueles descritos na literatura (Nardon, 2001b).

As características área de olho-de-lombo real e espessura de gordura não diferiram significativamente entre os grupos NeS e NeC. Quando a área de olho-de-lombo foi transformada para $100 \mathrm{~kg}$ de carcaça, os animais $\mathrm{NeS}$ apresentaram menores médias. Morris et al. (1993), trabalhando com animais Angus, não encontraram diferenças entre animais selecionados e não-selecionados para essas características.

Os valores encontrados para estas características foram bem próximos aos apresentados por Nardon (2001b) 
e Razook et al. (2001) e inferiores aos descritos por Luchiari Filho et al. (1989) para animais provenientes de vários cruzamentos de vacas Nelore e touros de origem européia e por Alleoni et al. (1997) para animais Caracu e Nelore de Sertãozinho.

A área de olho-de-lombo é um bom indicador da musculosidade da carcaça. Os animais Ca, em comparação aos $\mathrm{NeS}$ e NeC, apresentaram maior média para essa característica, porém, quando a medida foi transformada para 100 kg de carcaça, a média dos animais Ca não diferiu da dos animais NeC. Corte (1980) obteve área de olho-de-lombo de $81,4 \mathrm{~cm}^{2}$ para 1/2 Marchigiana: $1 / 2$ Nelore, $77,7 \mathrm{~cm}^{2}$ para os 1/2 Chianina: $1 / 2$ Nelore e $67,1 \mathrm{~cm}^{2}$ para os Nelore. Esses valores demonstraram diferenças acentuadas entre zebuínos e raças de maior porte para essa característica. Nardon et al. (1997), em novilhos zebuínos com pesos médios de 423, 512 e 521 kg, observaram área de olho-de-lombo de 61,3; 66,3 e $67,5 \mathrm{~cm}^{2}$, respectivamente.

A espessura de gordura não diferiu significativamente entre os animais $\mathrm{NeS}$ e $\mathrm{NeC}$, mas foi menor para os animais Ca que para os $\mathrm{NeS}$ e NeC. Esse fato pode ser explicado pelo tamanho corporal dos animais Ca ou pelas diferenças nas exigências nutricionais em relação aos zebuínos. Uma das características das raças de grande porte é a baixa deposição de gordura (Luchiari Filho et al., 1985).

Os valores de espessura de gordura foram inferiores aos reportados por Nardon (2001b), de 6 a 9,4 mm, porém, muito acima dos obtidos por Jorge et al. (1999) em animais Gir, Guzerá, Nelore e Tabapuã. Lunt (1985), comparando novilhos Aberdeen Angus, Brahman e cruzados Aberdeen Angus $\times$ Brahman em diferentes períodos de confinamento, concluíram que os zebuínos tiveram deposição de gordura antecipada em relação aos outros genótipos. Esse fato também pode explicar o comportamento dos animais Nelore em relação aos Ca para a característica espessura de gordura. Em estudos comparativos de diferentes cruzamentos, Crouse et al. (1989) concluíram que, quanto maior o grau de sangue zebuíno, menor a porcentagem de gordura intramuscular e maior a de gordura de cobertura.

\section{Conclusões}

A seleção no rebanho Nelore provocou maiores pesos de abate e de carcaça e refletiu também em maiores pesos dos quartos dianteiro e traseiro, porém sem alteração em seu rendimento em relação à carcaça. Animais Caracu, quando comparados aos Nelore, necessitaram de maior tempo de confinamento para atingirem $4 \mathrm{~mm}$ de espessura de gordura; apresentaram ainda menor rendimento de traseiro, maior proporção de ponta-de-agulha e rendimento de dianteiro semelhante. A seleção para peso não promoveu no rebanho Nelore alterações nos rendimentos da porção comestível total da carcaça e de seus quartos; o mesmo ocorreu para a proporção de ossos e aparas.

Animais Nelore Seleção apresentaram maiores valores para força de cisalhamento da carne em relação aos dos grupos Nelore Controle e Caracu, o que indica possibilidade de apresentarem carne menos macia em comparação a outros grupos, porém, dentro de padrões aceitáveis de maciez. A seleção não promoveu alterações nas perdas por cozimento da carne nos diferentes grupos genéticos.

\section{Literatura Citada}

ALlEONI, G.F.; LUCHIARI FILHO, A.; BOIN, C. et al. Características de carcaça e desempenho em confinamento de novilhos Caracu comparados com novilhos Nelore. ARS Veterinária, v.13, n.2, p.141-149, 1997.

CORTE, O.O. Composição e qualidade de carne de tourinhos Nelore, Nelore-Chianina e Nelore-Marchigiana. Boletim Técnico ITAL, v.5, p.1-10, 1980.

CROUSE, J.D.; CUNDIFF, R.M.; KOCH, M. et al. Comparisons of Bos indicus and Bos taurus inheritance for carcass beef characteristics and meat palatability. Journal of Animal Science, v.67, n.5, p.2661-2668, 1989.

JORGE, A.M.; FONTES, C.A.A.; PAULINO, M.F. Tamanho relativo dos órgãos internos de zebuínos sob alimentação restrita e ad libitum. Revista Brasileira de Zootecnia, v.28, n.2, p.374380, 1999.

LEME, P.R.; SILVA, S.L.; PEREIRA, A.S.C. et al. Desempenho e características de carcaça de animais Nelore, 1/2 Caracu x $1 / 2$ Nelore e $3 / 4$ Caracu x $1 / 4$ Nelore confinados com dietas de alto concentrado. In: REUNIÃO ANUAL DA SOCIEDADE BRASILEIRA DE ZOOTECNIA, 39., 2002, Recife. Anais... Recife: Sociedade Brasileira de Zootecnia/Gnosis, [2002] (CD-ROM).

LUCHIARI FILHO, A.; BOIN, C.; ALLEONI, G.F. et al. Efeitos do tipo de animal no rendimento da porção comestível da carcaça. 1. Machos da raça Nelore vs cruzados zebu x europeu terminados em confinamento. Boletim de Indústria Animal, v.42, n.1, p.31-39, 1985.

LUCHIARI FILHO, A.; LEME, P.R.; RAZOOK, A.G. et al. Características de carcaça e rendimento da porção comestível da carcaça de machos Nelore comparadas a cruzados (F1) obtidos do acasalamento de touros das raças Canchim, Santa Gertrudis, Caracu, Holandês e Suíço com fêmeas Nelore. 1. Animais inteiros terminados em confinamento. Boletim de Indústria Animal, v.46, n.1, p.17-25, 1989.

LUNT, D.K. Carcass characteristics and composition of Brahman, Angus and Brahman steers fed for different times on feed. Meat Science, v.14, p.137-152, 1985.

MARSHAL, D.M. Breed diferences and genetic parameters for body composition traits in beef cattle. Journal of Animal Science, v.72, n.10, p.2745-2755, 1994.

MORRIS, C.A.; BAKER, R.L.; BASS, J.J. et al. Carcass composition in weight-selected and control bulls from a serial slaughter experiment. Australian Journal of Agricultural Research, v.44, n.2, p.199-213, 1993.

NARDON, R.F.; TEDESCHI, L.O.; BOIN, C. et al. Características e composição de carcaças de zebuínos com diferentes índices de desempenho em provas de ganho de peso. In: REUNIÃO ANUAL DA SOCIEDADE BRASILEIRA DE ZOOTECNIA, 34., 1997, 
Juiz de Fora. Anais... Juiz de Fora: Sociedade Brasileira de Zootecnia, 1997. p.343-345.

NARDON, R.F.; SAMPAIO, A.A.M.; RAZOOK, A.G. et al. Efeito da seleção para peso pós-desmama no desempenho de bovinos em confinamento. Boletim de Indústria Animal, v.58, n.1, p.9-19, 2001a.

NARDON, R.F.; RAZOOK, A.G.; SAMPAIO, A.A.M. et al. Efeitos da raça do bovino e da seleção para peso pós-desmama na quantidade da porção comestível da carcaça e na qualidade da carne. Boletim de Indústria Animal, v.58, n.1, p.21-34, 2001b.

NOUR, A.Y.M.; THONNEY, M.L. Carcass, soft tissue and bone composition of early and late maturig steers fed two diets in two housing types and serially slaughtered over a wide weight range. Journal of Animal Science, v.64, n.3, p.1345-1355, 1987.

NORMAN, G.A.; FELÍCIO, P.E. Effects of breed and nutrition on the productive traits of zebu, Charolais and crossbreed beef cattle in south-east Brazil. 1. Body and gross carcass composition. Meat Science, v.5, p.425-438, 1981.

OWENS, F.N.; DUBESKI, P.; HANSON, C.F. Factors that alter the growth and development of ruminants. Journal of Animal Science, v.71, n.11, p.3138-3150, 1993.

PERON, J.A.; FONTES, C.A.A.; LANA, R.P. et al. Rendimento de carcaça e de seus cortes básicos e área corporal de bovinos de cinco grupos genéticos submetidos à alimentação restrita e "ad libitum”. Revista Brasileira de Zootecnia, v.22, n.2, p.239247, 1993.

RAZOOK, A.G.; FIGUEIREDO, L.A.; BONILHA NETO, L.M. Selection for yearling weigth in Nelore and Guzerá zebu breeds: selection applied and response. in 15 years of progeny. In: WORLD CONGRESS ON GENETICS APPLIED TO LIVESTOCK PRODUCTION, 6., 1998, Armidale. Proceedings... Armidale: New South WalesNew South Wales, 1998. p.133-136.
RAZOOK, A.G.; FIGUEIREDO, L.A.; CYRILLO, J.N.S.G. et al. Prova de ganho de peso: normas adotadas pela Estação Experimental de Zootecnia de Sertãozinho. Nova Odessa: Instituto de Zootecnia, 1997. 42p. (Boletim Técnico, 40).

RAZOOK, A.G.; FIGUEIREDO, L.A.; NARDON, R.F. et al. Efeitos de raça e da seleção para peso pós-desmame sobre características de confinamento e de carcaça da $15^{a}$ progênie dos rebanhos Zebu e Caracu de Sertãozinho (SP). Revista Brasileira de Zootecnia, v.30, n.1, p.115-124, 2001.

RESENDE, F.D.; NARDON, R.F.; RAZOOK, A.G. et al. Desempenho e características de carcaça de zebuínos e Caracu selecionados para peso aos 378 dias de idade, submetidos a dois níveis de energia na terminação. In: REUNIÃO ANUAL DA SOCIEDADE BRASILEIRA DE ZOOTECNIA, 37., 2000, Viçosa, MG. Anais... Viçosa, MG: Sociedade Brasileira de Zootecnia/Gnosis, [2000] (CD-ROM).

STATISTICAL ANALYSIS SYSTEM - SAS. [1999]. SAS online doc: version 8. Disponível em: <http://www.id.unizh.ch/software/ unix/statmath/sas/sasdoc/stat/index.htm.> Acesso em: 10/3/2005.

VITTORI, A.; QUEIROZ, A.C.; RESENDE, F.D. et al. Características de carcaça de bovinos de diferentes grupos genéticos, castrados e não-castrados, em fase de terminação. Revista Brasileira de Zootecnia, v.35, n.5, p.2085-2092, 2006. 